\title{
Merits and Arguments Related to Circumcision
}

\author{
Hosni Khairy Salem \\ Kasr Al Ainy Hospital, \\ Cairo University, Cairo, \\ Egypt
}

\section{Introduction}

Christians and no believers perform Circumcision for health and hygienic reasons especially in U.S.A. and some countries of the Middle East. It is uncommon in Northern Europe, Central and South America and Asia (Leitch, 1970). It is one of the" oldest operations but it has not received enough consideration or progress in the Middle East. It is always regarded as a minor outpatient procedure often performed by primitive clamps by barbers, Mohels, medical students and house officers (Kaplan, 1977).In hospitals, male circumcision is performed by junior gynecologists, urologists, or surgeons. The objective of this article is to perform a review of the literature regarding the different aspects of male circumcision and discussing the following points; history of circumcision, urgent indications of circumcision, merits and arguments related to circumcision, religious factors, contraindications of circumcision, timing of circumcision, different techniques of circumcision, complications after circumcision and relation to STDs or UTI.

\section{History of circumcision}

Circumcision is one of the oldest operation in the history and the first unequivocal description of circumcision is found in the forth dynasty Egyptian toombs (3000 BC). According to Herodotus, it was practiced at puberty. It is carved on portraits in the Karnak temple of Mount Saini Statues of Pharaohs. Its technique is seen in a bas brief on Mastaba of Sakkarah in the fifty dynasty (Bistschai\& Brodnay, 1956; Arnaout et al., 1962 and Badr, 1963). Whether it had a religious or hygienic in purpose in Ancient Egypt, it is unknown. According to Herodotus, the Egyptians taught the procedure to Jews, Syrians and Phoenicians. Later, the custom spread to Ethiopians but Herodotus did not know that Columbus would find the natives of the West Indias circumcised. Captain Cook found the practice used by natives of Australia, Fijt, New Caledonia, New Hebrides and Madagascar (Blandy, 1968).It is a religious ritual practiced by Jews and Muslims. Jews practice it on the eighth day after birth. From Jews, it passes to the Christians who performed it for hygienic purposes then passed to Muslims as an important ritual of cleanliness for males. It was introduced to the western cultures by Biblical injunctions (Arnaout et al., 1962). Circumcision has also been practiced in other locations and for various reasons throughout the world e.g., 
in the-one continent of Africa, only certain tribes circumcise e.g., Zulo, Xahsa, Bechuana and Falasha while among its many Christian communities; circumcision has a religious significance only in Ethiopia (Blandy et al., 1968).

\section{The prepuce (what is removed during circumcision?)}

The glans is covered by the prepuce which is formed of two layers of skin reflected at the neck of the penis behind the corona glandis; the inner layer of the prepuce is confluent along the line of the neck with thin skin-which covers and adheres firmy to the glans on the undersurface of the glans penis, a small median fold passes to the deep surface of the prepuce (frenulurn). The prepuce is separated from the glans by a potential space (preputial sac) which presents two shallow fossae on either side of the frenulum. On the corona glandis and on the neck of the penis, there are numerous small preputial sebaceous glands which secrete smegma beneath the foreskin (a mixture of sebaceous material and shed keratin). It has a peculiar odor, and may be seen exiting from the foreskin tip or accumulate in clumps beneath the foreskin (Gray's Anatomy, 1950).

\section{Indications of circumcision}

\subsection{Phimosis}

It is a condition in which the contracted foreskin cannot be retracted over the glans and the commonest cause is chronic infection from poor local hygiene. In diabetic older men, balanoposthitis may lead to phimosis (Eiger, 1972). Congenital narrowing of the preputial orifice associated with long foreskin leads to ballooning out of the prepuce on micturition with a thin weak stream of urine leading to difficult micturition with residual urine, hydroureter and hydronephrosis but more often occurs as a result of atresia meati which may lie hidden by phimosis (Blandy et al, 1968, Bailey \& Love's, 1992). It is reported that most cases of phimosis occur in uncircumcised males although excessive skin left, which may become stenotic lead to phimosis.

Circumcision has been the traditional treatment for phimosis but not the only management option; the best of which appears to be gentle physical retraction combined with topical steroid treatment of the unretractable foreskin (Dewan et al., 1996).

Circumcision for phimosis in infant and young boys is done due to a request by the patients (religious and personal), or due to recurrent balanitis with inability to retract the prepuce and rarely due to a very long prepuce. In adults, it is done due to inability to retract for intercourse, tight frenum, balanitis and sometimes, prior to radiotherapy for penile carcinoma.(Bailey\& Love's, 1992).

\subsection{Paraphimosis}

Tight prepuce has been retracted and cannot be returned to its normal position. This is due to chronic infection under the redundant foreskin which leads to contracture of the preputial opening (phimosis) and formation of a tight ring of skin when the foreskin is retracted over the glans. The skin ring leads to venous congestion which leads to engorged oedematous 
glans making the condition worse. As the condition progresses, arterial occlusion and necrosis of the glans may occur. Treatment can be done by firm squeezing of the glans for five minutes to reduce tissue oedema and to decrease the glans size then the skin can be drawn forwards over the glans. If this is unsuccessful, general anaesthesia must be given and the constricting band is incised and circumcision is done to trim the redundant skin later on and antibiotics should be given (Bailey \& Love's, 1992).

\subsection{Trauma}

It is a rare indication for circumcision (Blandy et al., 1968).

\subsection{Balanoposthitis}

Inflammation of the glans penis is known as balanitis while the inflammation of the prepuce is known as posthitis. Frequently, the opposing surfaces of the prepuce and glans are implicated in the inflammation process (Balanoposthitis).

The immediate cause of acute balanoposthitis is the multiplication within the preputial sac of pyogenic organisms as Streptococcal pneumococci and coliform bacilli. A contributing cause of balanoposthitis is diabetes (Manson, 1966 and Ross, 1941).

\subsection{Prophylactic neonatal circumcision}

Circumcision is done as prophylactic reasons to reduce the incidence of: urinary tract infection, penile carcinoma and carcinoma of the cervix "and sexually transmitted diseases.

\subsection{Religious reasons}

Circumcision is a religious rite among Muslims and Jews (Arnaout et al., 1962).

\section{Circumcision/sexually transmitted diseases (STDs) \&HIV}

Donovan et al. in 1994,stated that the uncircumcised penis is hypothetically at increased risk of STDs especially-genital herpes, gonorrhea, syphilis, immunodeficiency virus type 1 (HIV1) infection, candidiasis and chancroid due to larger surface area, thinner epidermal barrier, more liability for epithelial microtrauma and the moist warm neck under the foreskin favoring the persistence of fastidious microorganisms. However, none of these hypotheses has been proven. Moses et al. in 1994, in eighteen cross sectional studies from six countries reported a statistically significant association between male circumcision and the risk for HIV infection. Male circumcision should be considered as an essential strategy for AIDscontrol (Tyndall et al., 1996). Caldwell in 1996 reported that in parts of subsaharan Africa, nearly $25 \%$ of the population is HIV positive as a result of heterosexual transmission of the virus. Lack of circumcision makes men in this region particularly susceptible. Taylor and Rodin in 1975, reported that there was a positive relationship between lack of circumcision and genital herpes simplex virus infection (HSV). Simonsen et al. in 1988, reported that in a controlled study of Human Immunodeficiency Disease (HIV), they found that men who were uncircumcised were 2.5 times more likely to have HIV infection. 


\section{Circumcision/urinary tract infections}

Winberg's study in Scandinavia 1975, where circumcision is uncommon showed that in male infants with pyelonephritis, the prepuce is colonized with the offending organism. This only occurs during the first months of life where boys have a urinary tract infection more frequently than girls.

Ginsburg and McCracken in 1982, like Winberg found that early in life, the number of boys with acute pyelonephritis was greater than girls and 95\% of all boys with urinary tract infection were uncircumcised. The association between circumcision and infection has since been confirmed by Wiswell and Roscelle in two epidemiologic studies, the latest involving over 400,000 infants. That study showed that the incidence of urinary tract infection was only $0.1 \%$ when circumcision was performed. Finally, taking into consideration the fact that most males in these Scandinavian studies are uncircumcised, it may consider the prepuce as a risk factor. Wiswell and Roscelle in 1986 and Horzog 1989, stated that the infection rate in uncircumcised infants was ten times greater than in circumcised males. So, prophylactic neonatal circumcision is mandatory to reduce the incidence of UTI.

\section{Circumcision/carcinoma of the penis}

KuroviUa et al. in 1971 Stated that, Jews do not have cancers of the penis because they perform ritualistic circumcision upon their male children on the 8th day of life. Muslims also perform ritualistic circumcision. Compared with Hindus, who live in a similar environment but who do not circumcise, Muslims are relatively free from penile cancers while those who delay circumcision till boys are about 10 years of age; by that time, occult cancerous changes have become so well established beneath the prepuce that the disease can not be prevented. Study of men with cancers of the penis shows a high proportion with conditions of the prepuce that make its retraction difficult or impossible. Difficulty in retracting the prepuce especially in a man careless of hygiene is likely to result in accumulation and retention of the smegma, probably the exciting agent in the production of penile cancer. It is evident that the complete prophylaxis conferred by a well performed circumcision early in infancy is not produced by the circumcision of adults. When an infant is circumcised and the glans is no longer protected by the prepuce, a dense, thicker epidermis develops that-resists formation of cancer by chronic irritation. An association has been reported between cancer of the cervix and penis (Smith et al., 1980) . It has long been known that carcinoma of the cervix is rare in nuns and that the incidence of such cancer is low in populations in whom most males are circumcised (Blandy et al., 1968).

\section{Contraindications of circumcision}

Any penile abnormality in which the foreskin may be used in later reconstruction e.g., Hypospadias or Epispadias. Epispadius is a contraindicatios for circumcision.

1. In doubtful sex as male and female pseudo-hermaphrodism or true hermaphrodism where both ovaries and testes are present.

2. In anemic, marasmic or weak children as well as in the presence of acute disease or active infections.

3. Unfavorable general conditions, e.g., prematurity, uncorrected bleeding diathesis (Grimes, 1978). 


\section{The optimum age for circumcision}

The third week is the best time for circumcision because pain is minimal, bleeding is minimal, wound healing is perfect, and the risk of infection and psychological effects are minimal because the blood is still loaded with maternal antibodies with the near sterility of the skin of the neonate.

Circumcision can be done at any later healthy period preferably before school age.

If it is confirmed that the uncircumcised male neonate is at a higher risk of serious urinary tract infection than the circumcised one and therefore, the operation should be done shortly after birth.

Jewish ritual of circumcision on the eighth day is known to be more effective prophylaxis than procedures performed at the age between 4-14 years (Blandy, 1968).

However, operations performed at adolescence or later in life are completely attended with undesirable erections, protracted healing and infection (Arnaout et al., 1962).

In Muslim areas, circumcision is usually performed in the first few months of life. In Uganda and similarly in Kenya, circumcision age is 12-20 years.

Also, circumcision can be done in the first day of life provided no hypospadius, bleeding tendency or intersex is present.

\section{Different opinions \& arguments in neonatal circumcision}

It is a custom: The most important, arguments are those of custom and tradition.

It confers beauty: It is difficult to evaluate the consideration of beauty since these are subjective. In cultures where circumcision is norm, young women find the uncircumcised penis radiculously ugly. Young ladies refuse intercourse without wearing an appropriate brooch through his penis.

It promotes health: through the prevention of venereal diseases, cancer of the penis and cervix uteri. Hutchinsons in 1891, the greatest syphilologist suggested that, the presence of the foreskin constitutes a constant source of irritation leading to high risk of syphilis in early life and cancer in the aged. Penile cancer is never seen in a Jew and chancres are rare.

In some countries, insurance excluded infants under the age of 15 years. The reason was that the money used to pay for the possible unnecessary circumcisions would cover much of the cost of emerging neonatal and premature intensive care units. Circumcision is done when the boy is more than one day old and after he has been checked for bleeding tendency (Blandy et al, in 1968).

There are children who are brought in by their parents for circumcision for ethnic or social reasons (Shanon et al., 1979).

On the other hand, the risk cost- effectiveness and medical resources should probably be allocated to health measures of demonstrated value. Laumann et al. in 1997, in The National Health and Social life survey, indicated that there are no significant differences between circumcised and uncircumcised men in contracting sexually transmitted diseases. 
Also, uncircumcised men appear slightly more likely to experience sexual dysfunction especially later in life. Their results support the view that physicians and parents must be informed about potential benefits and risks of circumcision.

Tran and Giacomantanio in 1996, reported that the increased rate of penile cancer among uncircumcised men appears to justify the procedure but that alone is not sufficient justification. The final decision in neonatal circumcision should be made by parents with balanced counsel from the attending physicians. The Infectious Disease Committee of the Canadian of Society in 1996, stated that circumcision of newborns should not be routinely performed.

\section{Anaesthetic techniques during circumcision}

Circumcision may be conducted using a wide variety of general, regional and local anaesthetic techniques. The choice of an ideal anaesthetic technique depends upon surgical and patients factors. In addition, sedation is commonly used to supplement local anaesthetic based techniques as part of a so-called monitored anaesthesia care (MAC) technique.

\section{Methods of circumcision}

Circumcision is one of the oldest and commonest operations in medicine. There are several, methods aiming for completely exposure of the glans and complete excision of the prepuce.

In infants and neonates:

Primitive methods: Bamboo - Lazem - shield (Ritual Jewish Circumcision).

Standard methods: Bone forceps, surgical dissection - circumcision by the use of special instruments (Gomco clamp- plastibell device- Mogen clamp) (Holman et al,1990).

In older children and adults:

Dorsal slit and dissection technique-sleeve resection method.

In Sudan, Bamboo size of the glans is applied over the glans down to the corona to protect the glans inside it while the prepuce is pulled out over the outer surface of the bamboo and cut off at the appropriate level.

Blunt circumcision on clamps (lazem or kalloba) (Arnaout et al., 1962), made of non-cutting blades articulating at one end are widely used by village barbers in rural areas.

Ritual Jewish Circumcision: The Jewish ritual operation is usually done by a professional circumciser who is trained to do the operation as well as to observe the rituals. Circumcision is usually done in a Synagogue but now is done in hospitals.

\section{Complications of circumcision}

The common complications due to circumcision are not usually serious. These include:

1. Asymmetrical removal of the foreskin which may require recircumcision for cosmetic purposes. 
2. The suture line may become infected specially by Staphylococcal infection. (Annunziato and Goldbum in 1978).

3. Meatal stenosis is probably the most common potentially adverse result of neonatal circumcision. Lacking of the foreskin coverage leads to irritation and inflammation of the meatal tissues by the very alkaline urine formed after meals. This leads to stenosis or meatal adhesions. Formal meatotomy is required when the stream is very fine in calibre (Blandy et al., 1968).

4. Bleeding from an artery or vein. Shulman et al. in 1964, reported that the most common complication in 800 infants undergoing ritual circumcision by Mohels on the 8 th day of life in Jews is haemorrhage which occurs in ten patients.

5. Removal of excessive skin of the penile shaft along with the prepuce. On healing of the wound, the penis sets buried in the scrotum. This results in a concealed or denuded penis. Repair is complicated by the lack of the available skin to cover the shaft of the penis. (Radhakrishnan \& Reges, 1984).

6. If the urethra is grapsed in the circumcision clamp or from stitches placed in the urethra, the injury is usually a fistula at the corona (Shulman et al., 1964).

7. Penile glans amputation during circumcision. Sherman et al. in 1996, reported seven cases of traumatic amputation of the glans penis and/or urethra during circumcision due to errors in the circumcision technique. The excised glandular tissue remains viable up to eight hours after injury. Reanastomosis of the glans and/or urethra following distal amputation even when there is a delay in the surgical repair of up to eight hours is usually successful.

8. Gangrene of the penis and scrotum (Du-Toit \& Villet in 1979).

9. Complete avulsion of the skin of the penis and scrotum (Malherbe, 1975). Shulman et al. in 1964, reported that 1:800 would develop complications requiring admission to the hospital, e.g., necrosis of the glans, laceration of the scrotum and removal of the entire penile skin.

\section{Laser circumcision}

The laser beam cuts as well as controls bleeding from the skin, resulting in a very tidy wound. This technique allows exact proportions of skin and mucous membrane to be removed. Laser circumcision is the technique of choice for children circumcision and can also be applied to adult patients. Clinical comparative studies between the Neodymium:yttriumaluminumgarnet (Nd:YAG) laser and conventional circumcision in boys are very few. Vaos compared the clinical effects of the Nd:YAG laser contact technique with those of a conventional technique on the grounds of certain perioperative parameters, including operative time, length of hospital stay, postoperative complications and morbidity. Seventy-five patients undergoing circumcision were reviewed retrospectively. Operative time, length of hospital stay, and postoperative morbidity were analyzed. The study concluded the Nd:YAG laser contact technique is an effective laser-assisted procedure alternative to the conventional technique in circumcision with virtually no significant postoperative morbidity (Vaos,2004).

Similar study using Carbon dioxide laser circumcision found this technique to reduce operative time translating into cost effectiveness. Morbidity rates of laser circumcision compared favorably to those of conventional circumcision (How et al 2003). 


\section{Psychological effect of circumcision}

An early operation minimizes the potential psychological damage caused by genital surgery (Manley, 1982). Also, avoids sensitive phases of psychosocial development (maternal bonding, separation anxiety, development of genital body image, gender identity, and phallic awareness), the disruption of which is thought to predispose to psychological problems in later life. The age at which surgery took place was not associated with abnormal psychological adjustment later in life (Freud 1955).

\section{Conclusions}

The advantages of male circumcision are much more than the disadvantages and this explains the increased number of parents asking for circumcision for their male infants.

\section{References}

[1] Leitch I.O.W. Circumcision, A continuing engima Aust. ped. J.G. 59-1970.

[2] Kaplan G.W.: Circumcision. An overview current problemsi in ped. 7: 1; 1977.

[3] Bistschai J. and Brodney, ML: A History of urology in Egypt Cambridge, Mass-Riveside press; 1956.

[4] Arnaout H.; Elfiky G.F. and Sherif M.: Circumcision. Kasr-ElAini J Surg. 3:169; 1962.

[5] Badr M.M.: The History of urology in Ancient Egypt. L Intern. Coll. surgeons 39:404; 1963.

[6] Blandy J.P.: Circumcision Hospital Mediane. 3:551; 1968.

[7] Gray's Anatomy D.: D.Davis 4 ${ }^{\text {th }}$ ed. (254-585-1561- Langrnans green and co. 1950).

[8] Eiger MS.: The case for circumcision. Today's Health. (50)4: p. 14; 1972.

[9] Bailey and Love's, short practice of surgery. Urethra and penis, vol II, 21Ist ed; 1992.

[10] Dewan PA; Tieu HC and ChTeng BS.: Phimosis is a circumicsion necessary. J. Ped. Child. - Health. Aug.; 32(4):285; 1996.

[11] Manson-Bakr; PH.: Manson's 16th. ed; page 677 London 1966.

[12] Ross J.C.: Brit. J. Surg., 42,29,194; 1941.

[13] Donovan B; Bassett I and Bodsvorth NJ.: Male circumcision and common sexua, transmissible diseases in a developed nationsetting: Genitourim Med. Oct.; 70(5):317; 1994.

[14] Moses S; Plummer FA; Bradley JE; Ndinya-Acloal-Jo; Nagelkerke NJ and Roland- AR.: The association between lack of male circum. and risk for HIV. infection: A review of the epidemiological data: sex- Transm. Dis. Jul- Aug: 21(4): 201; 1994.

[15] Tyndall MVV; Ronald AR; Agoki E; iMalisa \V; Bvvayo JJ; Nadinya Achola Jo; Moses S and Plummer FA.: Increased risk of infeciion with human immunodeficency virus type 1 among uncircumcised men presenting with genital ulcer dis. in Kenya: clin. Infect. Dis. Sep; 23(3) 449; 1996.

[16] Caldwell JC and Caldwell P.: African AIDS, epidemic. Sci. Am. Mats; .274(3) 62; 1996.

[17] Taylor P.K.; Rodin P.: Herpes genitalis and circumcision. British Journal of veneral diseases, 51:274; 1975. 
[18] Simenson J; et al.: Human Immunodeficiency virus infection among men. Africa. Engl. J. Med. 319(5): p. 274; 1988.

[19] Winberg J; Bergstrom T and Jacobsson B.: Morbidity, age and sex distribution, recurrences and renal scarring in symptomatic UTI. In children. Kidney Int. 4(suppl.) 3:8-101-8-106; 1975.

[20] Ginsburg CM; MC Cracken GH Jr.: UTI. in young infants ped. 69:409; 1982.

[21] Wiswell TE and Roscelle JD.: Corroborative evidence for the decreased incidence of UTI. incircumcis. Male infants-ped. 78; 1986.

[22] Herozog L.W.: Urinary tract infection and circumcision: Acase Control, A, J, Did Child 143(3): pp 348-50; 1989.

[23] Kurovilla J.T.; Garlick R.H. and Nammon K.E.: Results of surgical treatment of penile'carcinoma: Aust. N.Z.J. surgery 41:157, 1971.

[24] Smith PG., Knlen IJ. White GC, et al.: Mortality of wives of men dying of cancer of penis. British Journal of Cancer. 41:422; 1980.

[25] Grimes DA.: Routine circumcision of the newborn infant: a reappraisal. Am. J. Obst. Gynecol. Jan. ID; ou (2): 125; 1978.

[26] Hutchinson J.: A plea for circumcision. Archives of surgery "'" 2:15; 1891.

[27] Shannon FT; Horvvood LJ and Fergusson DM.: Infant circumcision. N-Z-Med.-J. Oct. 10; 90 (645):283; 1979.

[28] Laumann EO; Masi CM and Zuckerman EW.: Circumcision in the United States prevalance, nrophylaclic effect? And sexual practice, JAMA.. April 2; 277(13): 1052; 1997.

[29] Tran PT and Giacomantonio M.: Routine neonatal circumcision. Can- Fam-Physician. Nov.; 42:2201; 1996.

[30] Holloman JR; Lewis EL and Ringler RL.: Neonatal circumcision techniques. Am. Fain. Physician. Aug., 52(2):511; 1995.

[31] Annunnziato D. and Goldbum L.M.: Staphylococcal scalded skin syndnome. A complication of circumcision. AM. J. Dis. Child. Dec; 132(12): 1187, 1978.

[32] Shuliman J.; Ben Hur N. and Neuman Z.: Surgical Complications of circumcision 9AmJ. Dis. Child 107: 149, 1964.

[33] Radhakrishnan, J. and Reges, H.M.: Penoplasty for buried penis secondary to radical circumcision, J. ped. surg., 199:6p 629; 1984.

[34] Sherman J; Borer, JG; Horowitz M; Glassberg KL: Circumcision successful glandular reconstruction and survival following traumatic amputation. J-uroi. Aug; 156 (2pt2); $842 ; 1996$.

[35] Du Toit DF and Villet WT.: Gangrene of the penis after circumcision S- Afr. Med- J. Mar. 24; 55(B) :521; 1979.

[36] Malherbe WD.: Injuries to the skin of the male external genitalia in southern Africa SAfr. Med-J. Feb. 1; 49(5): 147; 1975.

[37] Vaos. G. Photomedicine and Laser Surgery. August 2004, 22(4): 318-322 doi:10.1089/pho.2004.22.318.

[38] How A.,Ong C.,Jacobsen A.,Joseph V. Carbon dioxide laser circumcisions for children,Pediatric Surgery International,2003-04-0,Springer Berlin / Heidelberg SN - 0179-0358. 
[39] Manley C. Elective general surgery at one year of age: psychological and surgical considerations. Surg Clinics North Am 1982; 62: 941-53.

[40] Freud S. A Case of Hysteria: Three Essays on Sexuality and Other Works. London: Hogarth Press, 1955. 


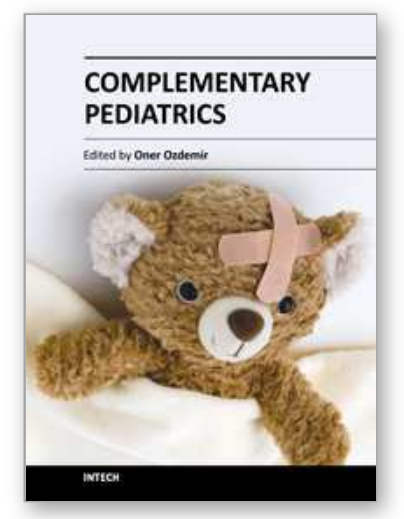

\author{
Complementary Pediatrics \\ Edited by Dr. Öner Özdemir
}

ISBN 978-953-51-0155-0

Hard cover, 354 pages

Publisher InTech

Published online 16, March, 2012

Published in print edition March, 2012

Complementary Pediatrics covers complementary issues of pediatric subspecialties consisting of ophthalmologic, surgical, psychosocial and administrative issues of frequently used medications. This book volume with its 16 chapters will help get us and patients enlightened with the new developments on these subspecialties' area.

\title{
How to reference
}

In order to correctly reference this scholarly work, feel free to copy and paste the following:

Hosni Khairy Salem (2012). Merits and Arguments Related to Circumcision, Complementary Pediatrics, Dr. Öner Özdemir (Ed.), ISBN: 978-953-51-0155-0, InTech, Available from:

http://www.intechopen.com/books/complementary-pediatrics/merits-and-arguments-related-to-circumcision

\section{INTECH}

open science | open minds

\section{InTech Europe}

University Campus STeP Ri

Slavka Krautzeka 83/A

51000 Rijeka, Croatia

Phone: +385 (51) 770447

Fax: +385 (51) 686166

www.intechopen.com

\section{InTech China}

Unit 405, Office Block, Hotel Equatorial Shanghai

No.65, Yan An Road (West), Shanghai, 200040, China

中国上海市延安西路65号上海国际贵都大饭店办公楼405单元

Phone: +86-21-62489820

Fax: $+86-21-62489821$ 
(C) 2012 The Author(s). Licensee IntechOpen. This is an open access article distributed under the terms of the Creative Commons Attribution 3.0 License, which permits unrestricted use, distribution, and reproduction in any medium, provided the original work is properly cited. 